\title{
Destinos afines: Emile Cioran, Yasmina Reza y la apología de la impugnación
}

\author{
Shared Destinies: Emile Cioran, Yasmina \\ Reza and the Apology of Rejection
}

\author{
Luis ViLlamía \\ Nazarbayev University, Kazajistán \\ luisvillamia@yahoo.es
}

\begin{abstract}
There is no doubt regarding the influence exercized by the work of Emile Cioran upon Yasmina Reza's fictional texts. Not only some of her theater characters are inspired in the figure of Cioran, but both writers share a similar worldview and analogous obsessions that flourish in their writings. In this manner, we do perceive in them a kind of aggressiveness that turns against themselves seasoned with frivolity and humor. In the speeches and monologues of Reza's characters we can identify ideas that are repeated endlessly in Cioran's aphorisms. Both authors turn reflection into pleasure towards excess, as if they were unable to contain themselves. From this perspective, we can better understand ideas such as their rejection from the notion of happiness for being considered a desire vulgar and childish, and the apology for barbarism as the only way to be reborn again.
\end{abstract}

\section{Key-words}

Nihilism, postmodernism, frivolity, aggressiveness, stateless.

\section{Résumé}

Il n'y a aucun doute sur l'influence exercée par l'oeuvre d' Emile Cioran dans les pièces de théâtre de Yasmina Reza. Non seulement certains de ses personnages s' inspirent dans la figure de Cioran, mais aussi les deux auteurs partagent une vision du monde similaire et les mêmes obsessions germent dans leurs écrits. Ainsi, on peut percevoir une sorte de agressivité qui se retourne contre eux mêmes accompagné de frivolité et humour. Dans les allocutions et monologues des personnages de Reza il est possible d'identifier des pensées qui se répètent sans cesse dans les aphorismes de Cioran. Les deux écrivains transforment la réflexion en un plaisir par l'excès, comme s'ils ne pouvaient pas s'empêcher de se contenir. Dans cette perspective il est possible mieux comprendre idées tels que le rejet de la notion de bonheur en le considérant un désir vulgaire et infantile, ou la apologie de la barbarie comme la seule forme de renaître.

\section{Mots-clés}

Nihilisme, postmodernisme, frivolité, agressivité, apatride. 


\section{Introducción}

La comparación entre Emil Cioran y Yasmina Reza no es baladí. Reza siempre ha reconocido la admiración que siente por el filósofo de origen rumano y la semejanza que percibe con su escritura, tanto en su mirada sombría al mundo como en su temperamento. El pesimismo de Reza, como ella misma ha reconocido en alguna ocasión, está aderezado de una vitalidad y de unos tintes humorísticos que también se advierten con claridad en Cioran. Pero este ascendiente sobre las obras de ficción de Reza no es meramente conjetural. Amanda Guiguere, en el único estudio publicado en inglés hasta la fecha sobre la obra de Yasmina Reza, The plays of Yasmina reza on the English and American Stage (2010), explica el curioso germen de la creación de una de las piezas teatrales de Reza: L'homme du hasard (1995). Reza no solo sentía devoción por Emil Cioran, sino que incluso llegó a redactarle cartas con mucha frecuencia que luego nunca enviaba. Una vez se encontró por la calle a Cioran, que vivió en París hasta su muerte en 1995, pero no tuvo el coraje de saludarlo. Este encuentro frustrado parece que fue el verdadero estímulo para la composición de la obra teatral L'homme du hasard. Según la propia Guiguere, la amargura que destila el personaje que encarna al escritor-Parsky- podría estar inspirado en el estilo de Cioran: ese detenimiento en sus propios fracasos pero siempre con cierto humor e ingenio y, sobre todo, desde un distante cinismo (Guiguere, 2010: 77). Incluso dentro de sus propias obras Reza ha citado en alguna ocasión a Cioran a modo de homenaje. En uno de los relatos autobiográficos que componen el libro Hammerklavier (1997), "Une chimère", la protagonista compra una revista con la única intención de leer un texto inédito de Cioran: "En ce jour amer, elle achète a la librairie Le Divan Le Messager européen, revue dans laquelle elle sait trouver un texte inédit de Cioran" (Reza, 1997: 62).

En líneas generales, vislumbrar las posibles analogías o el legado entre textos de contenido filosófico y obras íntegras de ficción es complicado porque se puede incurrir con facilidad en comparaciones arbitrarias o en vínculos forzados. Sin embargo, este caso se puede justificar con más facilidad porque la obra de Cioran no proyecta un sistema filosófico en el sentido tradicional, sino que se asemeja más a otros cauces de escritura especialmente fecundos en el siglo XX que se sublevaban contra las fórmulas filosóficas más convencionales y cultivaban una filosofía más intimista a través de unos textos de condición autobiográfica y aforística. Por su parte, no hay duda de que Yasmina Reza proyecta una sombría percepción de la condición humana, sobre todo en sus narraciones breves, aunque estén siempre aderezadas de un humor corrosivo. Noël Carroll incluso, en su artículo dedicado a la pieza teatral más afamada de Reza, Art (1994), inscribe esta obra en la categoría de "theater of ideas" (Carroll, 2002: 206). La literatura de Reza siempre invoca al otro, se erige en lo que Denis Guénoun denominó una "filosofía del diálogo" (Guénoun, 2005: 105). Una persona escogida por nosotros, como explica Carroll, es en cierta medida un espejo de nosotros mismos y por 
ello debe existir una simiente común en nuestro sentido del gusto o en el humor que cultivamos (Carroll, 2002: 206). Incluso el humor de Reza (una de sus señas de identidad) tiene una dimensión ontológica. La risa en estas obras es solo el desahogo de la ansiedad, de un instinto nervioso. En Cioran, como también sucede con Yasmina Reza, las pulsiones son el verdadero estímulo de su escritura, por ello sus inquietudes más importantes se repiten una y otra vez en sus textos. Se puede identificar fácilmente el estilo tan singular de Cioran y sin embargo al mismo tiempo todos sus libros son muy semejantes entre sí.

Estas pulsiones como verdadero acicate para la escritura son muy importantes para identificar los aspectos que tienen en común Cioran y Reza. Ambos escriben en estado de zozobra y desasosiego su insatisfacción vital. En alguna ocasión, Cioran ha declarado que lo que hace vivificante su perseverante negación es una naturaleza apasionada, es más, él no se define como pesimista, sino como violento (Cioran, 1995: 20). En un pasaje célebre de su obra, al comienzo de La tentation d'exister (1956), Cioran escribía: "nous devons la quasitotalité de nos découvertes à nos violences, à l'exacerbation de notre déséquilibre" (Cioran, 1956: 9). Pero esta agresividad que emana de su escritura siempre se torna contra él mismo, es un proceso incesante de pensar contra uno mismo: "le violent ne force sa nature, ne va au-delà de soi, que pour y rentrer en furieux, en agresseur, suivi de ses entreprises, lesquelles, viennent le punir de les avoir sucitées" (Cioran, 1956: 9). Susan Sontag, en el ensayo que dedicó a Cioran, lo explica muy bien: es una forma de pensar tortuosa, que se devora a sí misma, pero en este proceso de autofagia la meditación regurgita con mayor intensidad: "thinking that devours itself -and continues intact and even flourishes, in spite (or perhaps because) of these repeated acts of self-cannibalism [...] He is both suffering Prometheus and the remorseless eagle who consumes his perpetually regenerated entrails" (Sontag, 1969: 80-81). En uno de los aforismos incluido en Syllogismes de l'amertume (1952), unas palabras que Cioran dedica a Nietzsche podrían ser perfectamente aplicables a su propia obra como epílogo de su pensamiento: “C'est l'expert en déchéances, le psychologue, psychologue agressif, point seulement observateur comme les moralists. Il scrute en ennemi et il se crée des ennemis. Mais ses ennemis il les tire de soi, comme les vices qu'il dénonce [...] Toutes ses haines se portent indirectement contre lui-même" (Cioran, 1952: 45)

En el caso de las ficciones de Yasmina Reza, muchos de sus personajes son seres desasosegados e iracundos, pero por eso mismo son especialmente vulnerables, es decir, son incapaces de cualquier contención, están siempre expuestos. Esta vehemencia además, como sucede también con los textos de Cioran, se descarga también con frecuencia contra ellos mismos. El personaje de Nadine Chipman por ejemplo, en la novela breve Dans la luge d'Arthur Schopenhauer (2005), declara al hablar de su marido: "mon mari n'a jamais hésité à s'autodétruire, peut-on parler d'un goût masculin pour l'autodestruction?" (Reza, 2005: 18). La mujer en la pieza teatral L'homme du hasard, al reflexionar sobre el escritor Paul Parsky, concluye: "Vous, vous dites ne rien aimer, vous vous plaignez de tout, mais dans votre fureur, 
dans votre énergie à vitupérer. Je vois la vie même" (Reza, 1995: 24). En otra de las novelas breves de Reza, Une désolation (1999), Samuel confiesa: “Malheureux, je l'ai été. Absurdement hanté, absurdement désagrégé" (Reza, 1999: 27). Incluso el propio padre de Yasmina Reza, como se describe en la obra autobiográfica Hammerklavier, es incapaz de cualquier moderación, está totalmente sometido al devenir de sus emociones: "Mon père ne savait pas masquer ses émotions; c'était un trait étrange car on ne s'attend pas à une fragilité de cet ordre chez un homme d'âge mûr et qui a réussi sa vie sociale" (Reza, 1997: 47).

Sin duda, en el caso de ambos escritores la figura del padre ha tenido un papel preponderante en su visión del mundo, en esa mirada descarnada y "cruel" en su sentido etimológico, es decir, en su acepción de "crudo", que "chorrea y se recrea en la sangre". El padre de Cioran era un sacerdote ortodoxo y, como explica Matei Calinescu, tanto en Rasinari como luego en la ciudad de Sibiu, el padre siempre fue tratado con un respeto ceremonioso, le veneraban como si fuera un santo. Pero luego en el ámbito privado el joven Cioran era testigo de su carácter impetuoso y de sus enfados continuos. Como dice Calinescu: "lo sagrado y lo profano coincidían en una misma persona, ante la mirada de un niño" (Grau y Caneque, 2007: 122). En el caso de Yasmina Reza, no hay duda de que el padre encarna el paradigma de muchos de sus personajes masculinos y, como sucede con Cioran, la brumosidad y escasez de recuerdos de sus padres forja un desarraigo. Lo único que recuerda con claridad Reza de su padre es la "brutalité de certaines manières" (Reza, 2005: 56). No solo por tanto han heredado de sus figuras paternas una mirada determinada del mundo, sino que su sensación similar de desarraigo ha sido muy importante en la escritura de ambos. Tanto Cioran como Yasmina Reza se describen como apátridas. Reza en Nulle part (2005) señala: “je n'ai pas de racines, aucun sol ne s'est fiché en moi. Je n'ai pas d'origines” (Reza, 2005: 57). Cioran por su parte, en una entrevista con J. L. Almira comenta: "soy jurídicamente apátrida y eso corresponde a algo profundo, pero no ideológico ni político, es mi estatuto metafísico" (Cioran, 1995: 102).

Estos orígenes inciertos han sido muy importantes para desembocar en esta especie de nihilismo postmoderno que proyecta la obra de ambos. Uno de los fundamentos del pensamiento de Cioran es la negación de estructuras estables del ser y por ello desde su perspectiva el único sostén posible para cualquier filósofo serían algunas certezas precarias. Como señala Savater, la única certidumbre inexorable de Cioran es la inanidad del ser, una especie de vacío azaroso ajeno a cualquier explicación causal. En Syllogismes de l'amertume Cioran declara con su peculiar contundencia: "les individus ne sont que des postillons que crache la vie" (Cioran, 1952: 139). Ante esa insignificancia del ser humano, Cioran propugna la futilidad como genuino anhelo real y el único medio para llegar a ella sería la práctica del escepticismo: “je voulais vous proposer la futilité [...] Dans ma présomption, j’espérais y arriver par la pratique du scepticisme" (Cioran, 1956: 117). No hay que olvidar que Cioran siempre ha sido leído bajo este prisma de la postmodernidad desencantada. Durante mucho 
tiempo, a pesar de gozar de la amistad de grandes escritores como Michaux, Ionesco o Beckett, Cioran apenas era conocido. Solo a partir de los años setenta comenzó a seducir a los intelectuales franceses. Como explica Philippe Garnier, el inicio de su popularidad está muy vinculado con su obra De l'inconvénient d'être né (1973). Parece ser que la contundencia del título fascinó a los medios culturales parisinos y se repetía con frecuencia en las cafeterías de moda (Cañeque y Grau, 2007: 131). En gran medida, hay una correlación entre la popularidad de Cioran en los años setenta y ochenta, y la evolución de muchos marxistas parisinos desengañados hacia posturas más escépticas y postmodernas. La perspectiva pesimista, mordaz y cercana a la misantropía de Cioran se puso de moda y su figura comenzó a gozar de mayor reconocimiento. En aquel momento la obra de Cioran se convirtió en uno de los grandes emblemas de la postmodernidad.

Creo que en el caso de Yasmina Reza se puede señalar una trayectoria y un reconocimiento similar al de Cioran con unas décadas de diferencia. Su obra, sobre todo algunas de sus piezas teatrales de mayor éxito internacional, siempre ha sido interpretada y descifrada desde paradigmas próximos a la postmodernidad. Es cierto que Reza despuntó muy joven como dramaturga, a finales de los años ochenta, cuando todavía la creación teatral era un ámbito casi vedado para las mujeres. Asimismo, sus grandes inquietudes, las pulsiones que asolan su escritura, se alejan de miradas feministas convencionales. Como dice Amanda Guiguere, Yasmina Reza representa sin duda una "anomalía" (Guiguere, 2010: 151) dentro de las letras francesas. Pero indudablemente en su trayectoria literaria se vislumbra claramente un punto de inflexión: el éxito internacional sin precedentes que suscitó su obra de teatro Art (1994). Creo que esa repentina celebridad solo se puede entender desde unas coordenadas históricas muy concretas. Si analizamos el texto con cierta perspectiva, ya que la obra se estrenó hace casi 25 años, es una pieza teatral que reproduce de forma nítida e inteligible una mirada posmoderna que fue preponderante entre algunas clases sociales, sobre todo de París, en los años noventa. Solo así se puede explicar el célebre "equívoco" (si algo así fuera posible en la recepción de una obra) que radica en el germen de ese éxito superlativo. Reza en realidad había concebido una obra sombría, perturbadora y proclive por momentos al absurdo. Un conflicto sobre la amistad entre unos hombres con un temperamento desmesurado y algo histriónico (como suele ser muy frecuente en su obra). El famoso cuadro, el Antrios, solo debía ser el pretexto del conflicto, un gran hallazgo sin duda, pero algo secundario dentro de la obra. Sin embargo, en esas transferencias culturales que siempre comporta la traducción, la obra (que resultó un gran éxito tanto en Londres como en Nueva York) suscitó en el público anglosajón carcajadas hilarantes y el interés de la pieza enseguida se focalizó sobre todo en el célebre lienzo blanco. Esta mutación tan radical sobre las expectativas de la autora sin duda incomodó a Yasmina Reza. Es más, como recuerda Jaccomard en su libro Les Fruits de la passion. Le théâtre de Yasmina Reza (2013), la escritora no permite su representación en Francia desde 1996 porque cree que las adaptaciones alteran y deterioran en 
exceso su texto original (Jaccomard, 2013: 104). El público en realidad vislumbraba en la originalidad de la pieza de Reza una controversia sobre el valor del arte abstracto y la nueva percepción, tan postmoderna, de la cultura como mercancía o forma de "distinción" entre las clases acomodadas.

Como vemos, ambos escritores siempre han sido interpretados desde un paradigma postmoderno. Por ello es tan importante en sus obras cierta dimensión de frivolidad que sazonan sus textos. Como si Cioran y Reza encarnaran miradas profundamente sombrías y nihilistas pero desteñidas por la futilidad, dentro además de una atmósfera típicamente posmoderna de plena crisis de legitimidad de los ideales modernos acerca del progreso, la razón o la cultura. La frivolidad y el escepticismo, al menos según Cioran, están ineludiblemente entretejidos. En Précis de décomposition (1949), el filósofo rumano escribía: "Personne n’atteint d'emblée à la frivolité. C'est un privilège et un art c'est la recherche du superficiel chez ceux qui s'étant avisés de l'impossibilité de toute certitude, en ont conçu le dégoût" (Cioran, 1949: 17). La frivolidad es justamente el antídoto más imprescindible para no revelar nuestro verdadero rostro íntimo y vulnerable: "Sans ses artifices, comment ne pas rougir d'avoir une âme? Nos solitudes à fleur de peau, quel enfer pour les autres!” (Cioran, 1949: 18).

En la obra de Yasmina Reza la frivolidad es también una dimensión muy importante. Es una forma de tamizar y camuflar las tragedias que acechan en sus piezas teatrales. No hay que olvidar, como señala Salah El Gharbi en su estudio Reza ou le théâtre des paradoxes, que las obras de Reza han sido tildadas de "populisme chic" en alguna ocasión y menospreciadas por parte de la crítica francesa como un teatro "import-export" justamente por las dosis de superficialidad que vincularían sus piezas teatrales a comedias de boulevard (El Gharbi, 2010: 10-11). Hay una especie de contención de la pulsión dramática en muchos de sus textos. En el momento del estallido final de la típica catarsis trágica, Reza tiende a domesticar su exceso con una evasión cómica. Una sonrisa o una mirada pueden ser suficientes para deshacer la tensión y volver al orden anterior. Ya en su primera obra teatral, Conversations après un enterrement (1987), la predecible convulsión final entre Nathan, Alex y Élisa se refrena y en su lugar Álex repentinamente congrega a todos a la mesa para cenar el pot-au-feu. Frente a la aparente tragedia que se vislumbraba, se impone sin embargo la "garniture quotidienne" (Reza, 1987: 149). El cauce final de la obra no es el entierro del padre, ni el devenir de un triángulo amoroso, sino esas conversaciones aparentemente banales sobre las fresas y las grosellas del jardín o los ingredientes escogidos para la cena: puerros, zanahorias, nabos o pepinillos. Como dice Álex, uno de los hermanos de la familia en la obra, la escritura es aparentar desplazarse a un lugar hacia el que al final no se acude: “C'est exactement ça écrire, aller quelque part où no ne va pas" (Reza, 1987: 149). Es una extraña amalgama que ilustra bien las obras teatrales de Reza: una génesis inspirada en la vida más cotidiana coexiste con un despliegue de las fuerzas de la sinrazón en plena efervescencia, como dos dimensiones ineludibles para retratar la vida humana. El crítico Denis Guénoun, de forma esclarecedora, 
describió esta especie de des-dramatización que suspende la fatalidad inherente en la tragedia como "stratégie des poireaux" (Guénoun, 2005: 50), es decir, Reza se sirve de la irrupción de la vida ordinaria y trivial para reprimir el advenimiento de una desgracia devastadora. En una línea similar, Montserrat Serrano, en su análisis de la obra Conversations après un enterrement (1987), también advierte esta estrategia como algo consustancial al teatro de Yasmina Reza: "on frôle toujours la tragédie et ell est toujours écarteé, la "stratégie des poireaux" jouant en faveur du désamorçage des conflits" (Serrano, 2013: 423). Es exactamente la misma curiosa aleación que vislumbra Cioran en sus textos al ilustrar la condición humana: "ce mélange indécent de banalité et d'apocalypse" (Cioran, 1949: 11). La inquietud nunca encuentra sosiego, pero sí alterna con el devenir más cotidiano y superficial.

\section{Impugnación de la felicidad}

Uno de los aspectos donde confluyen con más claridad el ideario de Cioran y la cosmovisión de los personajes de Reza es justamente en la impugnación vehemente contra la felicidad. La zozobra y el desasosiego de la vida no se pueden conciliar con la serenidad de la felicidad. Cioran desde su disposición nihilista, que asume casi como un éxtasis negativo, considera que en el individuo solo puede prevalecer casi de forma inherente una condición de disconformidad. El ser nihilista es indómito y casi irreductible en su mirada fatalista y trágica. Como decía Cioran ya en su primera obra, Sur les cimes du désespoir (1934), "L’homme ne vit-il pas la tragédie d'un animal constamment insatisfait, suspendu entre la vie et la mort?' (Cioran, 1934: 50). No se puede por tanto claudicar al conformismo de la felicidad. Es una pretensión vulgar, una forma de banalizar la experiencia trágica que encarna la vida. Como expone el propio Cioran en La Chute dans le temps (1964): "pour ce qui est du bonheur, si ce mot a un sens, il consiste dans l'aspiration au minimum et à l'inefficace, dans l'en-deçà érigé en hypostase" (Cioran, 1964: 46). El anhelo de felicidad curiosamente se transfigura en una forma de resignación.

Entre los personajes de Reza también se censura con frecuencia la pretensión de felicidad, como si fuera una simplificación casi infantil de la vida. El narrador de Une désolation, al hablar de la pasividad de su hijo, comenta con desdén: “j'ai mis au monde un type heureux" (Reza, 1999: 11). Más adelante en la misma novela, el narrador, con un sarcasmo corrosivo que podríamos comparar con un aforismo de Cioran, se lamenta de la actitud hedonista y superficial de su hijo ante la vida, como si ser feliz fuera un atributo solo reservado para los conformistas: "mon fils veut le calme et la douceur, mon fils veut, dans la paix, penser ses minables plaies de l'âme [...] j'ai engendré un véliplanchiste" (Reza, 1999: 55). De hecho, si algo les resulta intolerable a muchos de los personajes de Yasmina Reza es esa disposición natural hacia la felicidad de algunas de las personas de su círculo. Martha, al hablar de su amigo Georges en la pieza teatral L'homme du hasard, rebela airada 'il était, ce qu'il y a de 
plus intolérable: heureux" (Reza, 1995: 27). El estado de felicidad en las ficciones de Reza solo denota ingenuidad y mansedumbre. Robert Toscano en la novela Heureux les heureux (2013) describe con maliciosa ironía el estado que proyecta Lionel Hutner como "c'est un homme qui cherche la joie, qui est en recherche de bonheur, mais de bonheur je dirais "cubique" (Reza, 2013: 48). La felicidad por tanto no solo es una quimera, sino que irradia una personalidad infantil y cierta indiferencia ante la vida.

Creo que para descifrar estas aseveraciones tan provocadoras hay que examinar no tanto cuál es la idea de felicidad que proyectan ambos en sus escritos, sino zambullirse en la mirada, sin duda semejante, con la que escudriñan el mundo. Hay en primer lugar en Cioran y en Reza un placer por la desmesura. Cioran decía que le gustaba compararse con el personaje de Macbeth justamente por la ampulosidad y la vocación de trangresión de Shakespeare. En los monólogos de los personajes de Reza o en los aforismos de Cioran parece que reflexionar solo es lícito si es un acto vehemente y extremo, una forma de exorcizar el rencor, como si escribir fuera una actividad terapéutica. Es decir, los textos de ambos escritores florecen desde un temperamento concreto, están en cierta medida sometidos a la fisiología. Dentro de la teoría de los cuatro humores de la que hablaba Hipócrates, tanto Cioran como muchos de los personajes más destacados de Yasmina Reza, se catalogarían sin duda como coléricos, como individuos donde predominaría la bilis amarilla. Cioran siempre se ha confesado una persona histérica, incapaz de dominarse, como él decía "un epiléptico frustrado" (Cioran, 1995: 27). Por su parte, entre los personajes de Reza, muchos de ellos están sometidos al imperio de los nervios. Michel por ejemplo le dice a Annette en Le dieu du carnage: "c'est nerveux. C'est une crise nerveuse [...] Je comprends que vous soyez angoissée [...] Moi je dis, on ne peut pas dominer ce qui nous domine" (Reza, 2006: 248). La psiquiatra en Dans la luge d'Arthur Schopenhauer dentro de sus conjeturas llega incluso a encontrar una razón moral en esta forma de reaccionar: "comme si l'empire des nerfs, si décrié, avait néanmoins sa raison d'être, je veux dire sa raison morale" (Reza, 2005: 70). La felicidad, entendida como un estado de grata satisfacción espiritual, es casi inasimilable en estos temperamentos tan alejados de cualquier forma de equilibrio o armonía. Experimentan más bien una continua perturbación del ánimo, una encarnación del furor en su sentido más etimológico, es decir, un extravío violento y una fuerte agitación. Cioran en La Tentation d'exister (1956) decía que el individuo había perdido la senda de la quietud y que ya solo tenía acceso a los secretos del desgarramiento. No solo sería por tanto consustancial al ser humano su perpetua insatisfacción y su naturaleza veleidosa, sino que para definir al individuo el filósofo rumano considera conveniente aplicar el oxímoron de "passionné du malheur" (Cioran, 1956: 10). No hay que olvidar que para Cioran incluso su omnipresente escepticismo es un "principe viscéral" (Cioran, 1956: 114). Esta subordinación fisiológica es fundamental para entender el pensamiento y la mirada al mundo de ambos escritores. El propio Cioran reconoce que en su escritura nunca parte de una idea, sino de un estado de ánimo, la idea viene solo después 
y condicionada por sus sensaciones previas, sobre todo por sus largas vigilias ocasionadas por el insomnio. La dimensión somática del ser humano nos aleja por tanto de la senda de la felicidad. Cioran en otras de sus obras, Syllogismes de l'amertume (1952), decía "toute expérience profonde se formule en termes de physiologie" (Cioran, 1952: 79). Pues bien, todos ellos, tanto Cioran como los personajes de ficción de Reza, son esclavos de sus nervios. Es una certeza que termina confesando Michel en Le dieu du carnage : "la vérité est que je n'ai aucun self-control, je suis un caracterériel pur" (Reza, 2006: 265).

Desde una dimensión metafísica, Cioran también justifica la incapacidad del hombre para alcanzar la felicidad. En su obra La Chute dans le temps (1964), Cioran rememora el mito de la expulsión del Paraíso - el relato de la caída-para apuntar una conjetura interesante: Adán ya debía padecer cierto malestar sin el cual no se podría explicar la facilidad con la que cedió a la tentación. Por tanto en el origen de la estirpe humana ya se podía vislumbrar esa "inaptitude au bonheur, cette incapacité de le supporter dont nous avons tous hérité" (Cioran, 1964: 12). Para Cioran el estado de felicidad no se adecua a la condición humana, solo puede ser la veleidad de un ser insustancial. Como ilustra en uno de sus textos: "Tous les êtres sont malheureux; mais combien les savent? La conscience du malheur est une maladie trop grave pour figurer dans une arithmétique des agonies ou dans les registres de L'Incurable" (Cioran, 1949: 46). En otro de sus libros, Bréviaire des vaincus (1944), cita en cambio otros rasgos más afines a nuestra naturaleza: el orgullo y la soledad. La experiencia vital arrastra al ser humano por otros estados más impetuosos y vehementes. Por ello, el individuo, inmerso en el vacío y sustentado únicamente en sus dos frágiles atributos desemboca en realidad en un estremecimiento más desgarrador que nada tiene que ver con ese bienestar cercano a la quietud. La verdadera plenitud de la vida, lo que Cioran denomina "flamme permanente" (Cioran, 1944: 48), comporta otras condiciones más acordes con la naturaleza humana: la venganza, "un aliment doux et fortifiant [...] un emportement qui engendre des sens par-dessus le nonsens général" (Bréviaire des vaincus 47), la intolerancia - esa singularidad del carácter tan acentuada también en los personajes de ficción de Reza-, o bien cultivar enemigos (Cioran, 1944: 48). Cualquier disposición antes que la insoportable monotonía de la quietud y de la paz.

Asimismo, este perfil humano que proclama Cioran se recrea constantemente en las ficciones de Yasmina Reza. Muchos de sus personajes, sobre todo masculinos, son egocéntricos, perciben al prójimo como un ser hostil y son intransigentes en su forma de ver el mundo. Esos largos monólogos que Reza cultiva en sus piezas teatrales o en sus novelas revelan personajes que se podrían identificar principalmente con esos atributos de los que hablaba Cioran: el orgullo y la soledad. Así, podríamos pensar en Paul Parsky, ese escritor ensimismado y amargado de la obra teatral L'homme du hasard (1995), Michel en Le Dieu du carnage, el académico sombrío y depresivo Ariel Chipman en Dans la luge d'Arthur Schopenhauer o, por supuesto Samuel, en ese monólogo cercano a la misantropía que representa Une déso- 
lation (1999). Estos rasgos distintivos de los que habla Cioran son los que el personaje de Samuel anhela en su hijo en Une désolation, en lugar de ese ser abúlico y pusilánime que ha creado y que además se jacta de ser feliz:

L'amusant de ça, c'est qu'au lieu de fabriquer un endurci, j'ai fabriqué un veule. Et je n'ai même pas engendré un ennemi [...] Il y avait chez toi, mon garçon, au moment de l'adolescence, un dérèglement des nerfs, une obsession de revanche, un côté brûlant [...] Les vapeurs de jeunesse passées, tu as repris ta place dans la moyenne [...] Tout ce qui nourrit un homme, le fortifie et l'entraîne au-delà de sa condition, tu l'as jeté aux oubliettes (106-110).

Muchos de estos personajes, como hemos visto, no solo tienen una visión muy sombría del ser humano, sino que son incapaces de contenerse. Son irascibles y eso es lo que hace tan tonificante y vital para ellos la negación y el repudio. La mirada al mundo de Reza en cierta medida impugna el mito de esa especie de bondad intrínseca que envuelve al ser humano. No es casual que Reza haya titulado una de sus narraciones Dans la luge d'Arthur Schopenhauer. Como señala Hélène Jaccomard en uno de sus artículos, Reza tiñe a sus personajes con ese pesimismo incisivo tan característico de Schopenhauer: "with words and actions Alan debunks myths of mankind's intrinsic goodness in the tradition of a philosopher Reza has often referred to in her plays, Arthur Schopenhauer. Schopenhauer is known for his fundamental pessimism: man's life swings like a pendulum backwards and forewards between pain and ennui [...] Human beings delude themselves about the nobility of their motives: what motivates them is a directionless will" (Jaccomard, 2016: 5). Pero no hay que olvidar en cualquier caso el afán de provocación en estos escritos. Hay siempre tras ellos un horizonte de ironía. Matei Calinescu hablaba de una fórmula en Cioran que exprimía una y otra vez porque tenía mucha fuerza literaria: una condensación del sentimiento autoparódico y a la vez desgarrador (Cañeque y Grau, 2007: 112). Esta impugnación de la felicidad no se entendería totalmente sin cierta presencia de la parodia, que tanto en Reza como en Cioran es de una inclinación histriónica y casi agresiva. En una de las novelas de Reza formada por todo un mosaico de personajes diversos, Heureux les heureux (2013), Lionel, uno de ellos, decide confesar a sus amigos el terrible drama de su hijo y despliega una carcajada pavorosa y turbadora: “dès qu'il a prononcé le nom, Lionel s'est mis à rire en postillonnant, d'une façon irrépressible, les yeux embués et rouges et le corps secoué de spasmes. Ça nous a pétrifiés de le voir rire comme ça" (Reza, 2013:133). Es un tipo de humor que emana casi de una actitud nihilista. Es algo que Cioran explicó bien en su obra Sur les cimes du désespoir. No se trata por tanto de una forma de ironía elegante y sutil que permite exhibir la sagacidad de la inteligencia. Cioran habla más bien de una ironía emparentada con la amarga desesperación (Cioran, 1934: 156). Una expresión de desahogo que podría sustituirse por una lágrima o por un espasmo. Es la cristalización de una "crispation intérieure" (Cioran, 1934: 98), de una absoluta ausencia de comprensión humana (Cioran, 1934: 157). Una carcajada siniestra 
que no se puede evitar y que revela la desolación de un mundo íntimo oscuro. Es una parodia siniestra de dos escritores que denuncian la fragilidad del progreso de las sociedades civilizadas de Occidente. Este tipo de felicidad no solo es una quimera para el ser humano, sino también un fraude, una estafa.

\section{Parisinos apátridas}

Hay otra dimensión en la que Cioran y Reza indudablemente se asemejan: su condición de apátridas, la sensación de un profundo desarraigo. Naipaul decía en su obra The Enigma of Arrival (1987) que esa especie de altruismo consensual hacia los oprimidos y los humillados tan extendida en los últimos tiempos falseaba la atroz desdicha de ser un exiliado. A Cioran el régimen comunista rumano no le permitió la entrada durante mucho tiempo y sus obras estuvieron prohibidas en su país de origen hasta 1989, pero ni Cioran ni la propia Yasmina Reza padecieron el destierro. De hecho, como explica Cacciari, la experiencia del exilio no es exactamente la de un simple desarraigo porque el que padece tal experiencia no deja de tener una tierra, un lugar adonde volver o al menos rememorar (Cacciari 90). La impresión de desarraigo, más cercana quizá a la sensación de perplejidad y extrañeza que a la de dolor, es probablemente una evocación más ajustada en los casos de Cioran y Yasmina Reza. Aunque, como veremos, no es una desazón similar en uno y otro.

Ciertamente, como han explicado numerosos sociólogos y antropólogos, la identidad y el sentido de pertenencia es una construcción que se relata, pero como dice Cioran no hay duda tampoco de que "poursuivis par nos originies, nous les sommes tous" (Cioran, 1960: 8). Los dos autores, en cualquier caso, no solo se definen como apátridas, sino que han tenido una relación compleja, fascinante y traumática, tanto con la ciudad de París, donde ambos han vivido la mayor parte de su vida, como con el idioma francés. A Cioran, que se trasladó a París en 1937 como becario del Instituto Francés de Bucarest, le gustaba describirse como un "apátrida metafísico", un sentimiento similar al de los estoicos del Imperio Romano que se declaraban "ciudadanos del mundo", es decir, que no eran ciudadanos de ninguna parte (Cioran, 1995: 25). Por su parte, una de las grandes inquietudes de Yasmina Reza, otra de las pulsiones de su escritura podríamos decir, es también su condición de irremediable desarraigo, esto es, unos orígenes inciertos. Desconocer prácticamente todo de su padre ruso y de su madre húngara. Ella misma lo ha reconocido en alguna entrevista: “j'ai toujours eu le sentiment d'être un peu apatride, et j'éprouve une forte nostalgie d'un monde finissant, celui des juifs d'Europe centrale et de la Vienne d'autrefois, qui fut une ville d'une extrême créativité" (Simmonet, 2000).

El anhelo de pertenencia a una comunidad proyecta en realidad en los dos escritores una añoranza por la infancia, la necesidad de convivir con un "paraíso perdido", un sentimiento similar al que evocaba Rilke. Cioran en su obra Histoire et Utopie (1960) escribía: 
“'La patrie n'est qu' un campement dans le désert' est-il dit dans un texte tibétain. Je ne vais pas si loin: je donnerais tous les paysages du monde pour celui de mon enfance" (Cioran, 1960 : 8). En el caso de Cioran, como muy bien señala Tulbure, hay que ser cuidadosos con la noción que despliega de "patria" porque se trata en realidad de un significante vacío que condensa múltiples connotaciones (Tulbure, 2016: 152). En ocasiones el sentido de "patria" no solo se yuxtapone al de sujeto, sino que en toda su obra se vislumbra un constante paralelismo entre una cultura y el cuerpo biológico, emulando la teoría de Oswald Spengler (151). Sus análisis de las civilizaciones tienden siempre a la abstracción, no se suelen examinar desde una contingencia histórica determinada. El criterio para catalogarlas y estimarlas es en realidad la pauta del "impulso vital" que adopta de la filosofía de Bergson (Tulbure, 2016: 158).

Yasmina Reza por su parte, en sus obras más autobiográficas confiesa la turbadora sensación de que le han escamoteado la infancia. En Nulle part (2005) expresa con amargura ese desarraigo, este levitar por el mundo sin un sentido de pertenencia, es decir, la nostalgia de una falta de tradición a la que poder adherirse: "je ne connais pas les langues, aucune, langue, de mes père, mère, ancêtres, je ne reconnais ni terre ni arbre [...] il n'y a pas de sol où j'éprouverais la nostalgie brutale de l'enfance, pas de sol où écrire qui je suis, je ne sais pas de quelle sève je me suis nourrie [...] ni le mot exil (Reza 2005: 55). Guénoun, en su obra dedicada a Yasmina Reza, también advierte de esa singularidad de las ubicaciones en sus textos o, como él mismo dice, de "ese no-lugar": Reza "semble déjouer toute tentative d'attache à un lieu d'origine, un enracinement. Cette écriture paraît s'engager à partir d'un déplacement et non d'un site. Comme une parole migratoire, où les positions spatiales seraient toujours passagéres, fugitives" (Guénoun, 2005: 44).

En los casos de los dos autores por tanto los orígenes determinan claramente su escritura y quizá también su relación paradójica con París, con la que se sienten profundamente identificados, pero de la que desdeñan su artificiosidad y la predilección por adoptar las modas más sofisticadas, sobre todo entre sus clases más acomodadas. La ciudad en ambos se recrea simultáneamente como un lugar estimulante y opresivo. Cioran escribía: "cette ville, que je n'echangerais contre aucune au monde, est pour cette raison même la source de mes malheurs" (Cioran, 1960: 28). Yasmina Reza también siente veneración por París, pero la mayoría de sus piezas teatrales están cargadas de sarcasmo contra la sociedad pudiente parisina y, a pesar de su abrumador éxito internacional, la crítica literaria de París casi siempre ha sido suspicaz y recelosa con su obra literaria.

Esta posición particular vincula a ambos escritores con la categoría de "extranjero" de la que hablaba Georg Simmel. A Cioran se le ha tildado como un escritor "fronterizo" y en el caso de Yasmina Reza en alguna ocasión se ha recalcado la condición cosmopolita de sus obras. Los dos son en cierta medida "metecos" como decía Cioran. Desde esta categoría de Simmel, las personas pueden perfectamente sentirse extranjeras en su propia tierra, como 
Reza, porque obviamente los individuos no son extranjeros en sí mismos, sino que lo son siempre para alguien. Ser extranjero por tanto es una construcción, que además encarna un papel ambiguo (y fundamental) dentro de una comunidad por su posición en cierta medida paradójica que combina de forma dialéctica proximidad y lejanía. El "extranjero", como dice Simmel, todavía no ha superado la ausencia de vínculo, (de "pertenencia”), propia del ir y venir. Es lo que Reza repite tantas veces: “je n'ai pas de racines, aucun sol ne s'est fiché en moi. Je n'ai pas d'origines" (Reza, 2005: 57). Hay incluso otra categoría que han utilizado algunos sociólogos que quizá se ajuste aún más a la posición desde la que escriben ambos o, al menos, desde la que se conciben a sí mismos. Se trata de la categoría del "extraño", es decir, aquellos individuos definidos como "no-miembros" de una comunidad. Serían una especie de outsiders culturales que en cierta medida desfiguran las fronteras culturales y sociales al hacerlas más porosas e inestables. La condición híbrida del extraño perturba los límites culturales preexistentes en cualquier comunidad. Una de las aversiones viscerales de Cioran era justamente la tentación del exiliado de "integrarse" en su nueva comunidad. Es preferible mantener lo que él denominaba una "situation limite" (Cioran, 1956: 66), cercana al estímulo poético. El exiliado, según Cioran, debía justamente ahondar en las llagas de su propia singularidad y anhelar ser de ninguna parte (Cioran, 1956: 67).

Las raíces de ambos no solo les proporcionó una mirada al mundo particular, sino que determinó su forma de escribir en francés. Como es bien sabido, uno de los grandes méritos de la obra de Cioran fue la decisión de modificar el idioma de su escritura y perfeccionar su talento con tanta destreza. De hecho, dentro del canon literario su obra está catalogada dentro del ensayismo lírico. En 1947, a los 37 años, Cioran experimentó una especie de catarsis mientras traducía a Mallarmé al rumano. Sin embargo, él siempre ha declarado su incomodidad con la lengua francesa. Considera que tiene una estructura demasiado rígida y que se amolda mal con su temperamento indómito. En cambio el rumano, mezcla de eslavo y latín, "es un idioma desprovisto de elegancia, pero de lo más poético" (Cioran, 1995: 109). En el caso de Yasmina Reza, su relación con el idioma también tiene atributos singulares justamente por la particularidad del francés que siempre ha escuchado en su entorno familiar: “Je ne crois pas écrire comme une Française: j’utilise des raccourcis, des formules très elliptiques, qui viennent de ce maniement étrange de la langue que l'on pratiquait autour de moi, cette façon de dire les choses indirectement, cet humour..." (Simmonet). Serían por tanto dos modelos de expresiones literarias con un "fuerte coeficiente de desterritorialización”, como decían Deleuze y Guattari (1975: 28). Cioran tensa el idioma con una fuerte carga simbólica y lo desmenuza en aforismos. Reza por su parte despoja a sus textos de cualquier ornamento artificial hasta cultivar una sobriedad donde solo perdura el diálogo. 


\section{Civilización y barbarie}

Para Cioran el artificio y la vacuidad de la sociedad civilizada, al menos en Occidente, ha sido profundamente tóxica en el devenir del ser humano. La sociedad del bienestar, el concepto de "vivir bien", ha mutilado el espíritu de los individuos. Esta es una idea sobre la que Cioran vuelve una y otra vez. Es una de sus "certidumbres viscerales". Desde su perspectiva, en las civilizaciones sobrevienen ciclos naturales y, tras ellos, la propia sociedad comienza inevitablemente a socavar sus propios valores y se desploma con ellos. En esta fatalidad de la decadencia, como dice Cioran, "la barbarie apparaît comme l'unique remède" (Cioran, 1964: 78). Este "apetito de destrucción" siempre ha sido una de las máximas de Cioran. El declive y la devastación de las civilizaciones constituye para él una especie de fascinante arcano lleno de belleza. Como señala en Précis de décomposition: "Comment tourner ses regards vers les époques crépusculaires [...] sans s'attendrir sur ce grand art qu'est la mort d'une civilisation?" (Cioran, 1949: 27). Ya con apenas veinte años escribió un artículo en rumano, “Apologie de la barbarie" (1933), que condensaba algunas de estas ideas con la vehemencia que siempre le ha caracterizado. Hay una correlación de conceptos indispensable entre la apología de la barbarie y la decadencia: "Nul ne peut avoir conscience du phénomène barbare s'il n'a pas expérimenté subjectivement toute la complexité du phénomène de la décadence' (Cioran, 1933: 50). La visión apocalíptica de la decadencia se transfigura en una impresión apocalíptica de la barbarie y solo desde sus desechos puede renacer "l'aurore d'une culture" (Cioran, 1933: 50). No hay que vislumbrar por tanto el advenimiento de la barbarie desde el temor al caos, sino que hay que discernir su fecundidad: “car dans la barbarie le chaos n'est pas un vide, mais l'unique réalité capable de provoquer l'apparition d'une aurore" (Cioran, 1933: 53). La convulsión de la destrucción y la barbarie siempre es preferible a la lenta podredumbre de la decadencia. El brote de la barbarie no solo es una explosión de fuerza y energía, según Cioran, sino que además aviva el orgullo de los individuos. Esta sacudida de barbarie de la que habla Cioran es en realidad "une barbarie intérieure" (Cioran, 1933: 55), es decir, una transfiguración radical de los valores y de la mentalidad del ser humano.

Cioran pensaba que su propia época, la segunda mitad del siglo XX, era fiel reflejo de un período en decadencia de la civilización occidental. La sofisticación excesiva de la civilización en la vieja Europa había alienado al individuo por su sentido de la decencia. La filosofía y su búsqueda de la felicidad había domesticado al ser humano, había "yugulado" todos sus instintos: "les traces du barbare qu'il fut, on les chercherait en vain: tous ses instincts sont jugulés par sa décence. Au lieu de le foutter, d'encourager ses folies, ses philosophes l'ont poussé vers l'impasse du bonheur" (Cioran, 1956: 33). En uno de sus ensayos más célebres, "Sur une civilisation essoufflée", Cioran vislumbra el punto de inflexión de la decadencia de la civilización en la época de la Ilustración. Como decía Susan Sontag, una de las vertientes del pensamiento de Cioran confluye con el tradicional desprecio romántico por la "intelec- 
tualidad" y la hipertrofia de la mente sobre la dimensión corporal del individuo: "A strange dialectic in Cioran [...] On the one hand, the traditional Romantic and vitalist contempt for "intellectuality" and for the hypertrophy of the mind at the expense of the body and the feelings and of the capacity for action" (Sontag, 1969: 87).

En el caso de Yasmina Reza, sus personajes de ficción sienten la misma desconfianza hacia algunos de los valores básicos que predominan hoy en día en las sociedades más sofisticadas de la civilización occidental. Norbert Elias decía que algunos de los instintos más elementales del ser humano se habían "refinado" debido a una serie de reglas colectivas y de convicciones que han desembocado en auto-coacciones (Elias, 1939: 293). Sin embargo, para los personajes de Reza esta contención voluntaria de las pulsiones es una) forma de alienación que repudian. Han abandonado cualquier forma de decoro porque consideran estos códigos de conducta grilletes para la condición humana. El personaje de Samuel en su novela breve Une désolation dice: “je suis hélas incapable de modération [...] Taire ou tiédir ce qui en soi bouillonne devrait être à la portée de n'importe quel être civilisé, mais j'ai cessé, figurez-vous, de vouloir paraître tel, et cessé par là même de nuire à ma santé” (Reza, 1999:75). En la obra teatral Le dieu du carnage, Alain, tras el fracaso del civismo y de la cortesía con el matrimonio Houllié, exclama la condición bárbara y la fatalidad que envuelve al ser humano: "Véronique, moi je crois au dieu du carnage. C'est le seul qui gouverne, sans partage, depuis la nuit des temps" (Reza, 2006: 280). Como dice Jaccomard, en un artículo excelente dedicado a la presencia del humor en esta pieza teatral, toda la obra en sí "repose sur la théorie que la civilisation est incapable de contrôler la violence des instincts" (Jaccomard, 2016: 190). Nadine Chipman en su monólogo de la obra Dans la luge d'Arthur Schopenhauer señala con cierta mordacidad una idea muy similar a la de Cioran: la filosofía solo ha servido para intentar contener la bestia indómita de nuestros espíritus: "la philosophie qui en gros, sous des allures plus ou moins provocantes, s'est toujours attachée à calmer les esprits, à réduire la bête sauvage, notre meilleure part" (Reza, 2005:19). El monólogo de la psiquiatra en esa misma novela es aún más fiero y brutal: “j’ai senti remonter la barbarie, la violence que j’affirme légitime" (Reza, 2005: 73). Incluso en su primera obra teatral, Conversations après un enterrement (1987), el personaje de Nathan explica que tanto él como Édith son personas civilizadas, que acatan ciertas reglas de conducta, aunque desconoce el propósito de ellas, pero Alex en cambio vive en otra dimensión por su orgullo desmesurado, en la barbarie: "nous sommes des gens civilisés, nous souffrons avec des règles, chacun retient son soufflé, pas de tragédie... Pourquoi au fond? Je n'en sais rien, mais c'est comme ça. Toi et moi, nous participons à cet effort de dignité... Nous sommes discrets, “élégants", nous sommes parfaits...Alex n'est pas moins civilisé, mais son orgueil est ailleurs...Ailleurs” (Reza, 1987: 95).

Cioran, como los personajes de esta pieza teatral de Reza, también abominaba de las costumbres sofisticadas y del sentido de la urbanidad y decoro justamente por lo que proyectaban de artificial y adulterado en el individuo. No es extraño por ello que de entre todas las 
grandes figuras pertenecientes a la Grecia Antigua, Cioran sintiera una especial fascinación por Diógenes el Cínico. El personaje que había sido capaz de "braver toutes les conventions" (Cioran, 1949: 94) o de verbalizar cualquier pensamiento con un grado superlativo de insolencia. Diógenes se convierte así para Cioran en un arquetipo ejemplar, aquel que podríamos llegar a ser "si l'éducation et l'hypocrisie ne refrénaient nos désirs et nos gestes" (Cioran, 1949: 94). Cioran se sentía profundamente identificado con esta figura histórica, no solo por el desprecio que sentía Diógenes hacia el resto de individuos, sino porque ese comportamiento desmesurado e histriónico de un hombre extravagante y austero deambulando por Atenas, que vivía en una tinaja y que buscaba con enojo algún ejemplo de hombre honrado, le parecía la encarnación de la lucidez y de la sinceridad: "Socrate devenu fou", ainsi l'appelait Platon. "Socrate devenu sincère", “c’est ainsi qu'il eût dû le nommer" (Cioran, 1952: 95).

Este caos que, según Cioran y Yasmina Reza, asola a la ajada civilización de la sociedad europea y a sus costumbres se vislumbra con especial énfasis entre los individuos más cultivados. Es el paradigma de lo que Cioran denominaba "intellectuel fatigué" (38). La tiranía del pensamiento no solo anula la capacidad de acción, sino que algunos individuos "overcivilized", como señala Susan Sontag en su artículo dedicado a Cioran, pueden desmoronarse por falta de estímulos "into a vulgar and passive barbarism" (Sontag, 1969: 85). El atributo más visible de la decadencia de la civilización europea sería por tanto este perfil de intelectual cansado. Una crítica similar a los intelectuales y académicos la encontramos en las ficciones de Yasmina Reza. Los individuos que destilan mayor amargura y agresividad suelen ser personajes de una clara vocación intelectual. Están especialmente incapacitados para ese "art de vivre ensemble" del que hablaba Véronique en la obra teatral Le dieu du carnage. Así podríamos citar a Alex, ese crítico destemplado de Conversations après un enterrement incapaz de escribir ficciones porque no tiene nada que decir, Georges, el escritor amargado y resentido de la pieza L'homme du hasard, Hubert Finidori, el académico arrogante y maltratador de Trois versions de la vie, o Ariel Chipman, el profesor de filosofía misántropo y abatido de la novela Dans la luge d'Arthur Schopenhauer. Todos ellos son personajes tóxicos e irascibles, más próximos a comportamientos desmesurados y crueles que el resto. Tanto Cioran como Reza proyectan una visión profundamente sombría de la cultura y de la civilización, y los intelectuales representan el mayor emblema de esta decadencia.

No hay duda por tanto de las múltiples analogías que podemos encontrar en Cioran y en Yasmina Reza. No es solo que Reza percibiera en Cioran un modelo y una influencia primordial en su escritura, sino que podemos decir que Reza, con el paso de los años, se ha convertido en la más insigne heredera de esa especie de nihilismo posmoderno que Cioran cultivaba con tanta vehemencia. Dos prototipos de escritura de un temperamento irascible. Pero en mi opinión la semejanza de la obra de estos dos escritores no es una circunstancia eventual, sino que en realidad ambos se adhieren a un cauce más amplio dentro de una tradición de las letras francesas: la de los moralistas franceses. Es decir, aquella nómina de 
escritores, sobre todo del siglo XVII, que no es que propugnaran una moral determinada, sino que eran observadores de su propio entorno y tendían a describir el mundo, las costumbres y las pasiones de sus coetáneos. No es extraño por ello que Blaise Pascal fuera uno de los escritores más admirados por Cioran. Savater ya identificó a Cioran con esta corriente: "Cioran está muy vinculado a los moralistas franceses. Casi no se puede entender a Cioran sin ellos. Él mismo es, de alguna forma, un moralista del tipo La Rochefoucauld" (Cañeque y Grau, 2007: 28). En el sentido de la crítica y el desprecio hacia algunas costumbres de su propia sociedad, tanto los aforismos de Cioran como las ficciones de Reza parecen rememorar a aquellos escritores. Incluso también en la mirada sombría que asola la escritura de ambos. Pero, en cualquier caso, serían moralistas posmodernos y frente a la decadencia de la civilización, ninguno de ellos se indigna ofendido, sino que más bien esbozan una sonrisa paródica y nerviosa que les permite distanciarse de su propia realidad.

\section{Referencias bibliográficas}

Carroll, Noël. 2002. "Friendship and Yasmina Reza's Art" in Philosophy and Literature 26 (1): 199-206.

Cioran, Emile. 2015 [1933]. Apologie de la barbarie. Paris, L'Herne.

Cioran, Emile. 1991[1934]. Sur les cimes du désespoir. Paris, Gallimard.

Croran, Emile. 1993 [1944]. Bréviaire des vaincus. Paris, Gallimard.

Cioran, Emile. 1944. Précis de décomposition. Paris, Gallimard.

Cioran, Emile. 1952. Syllogismes de l'amertume. Paris, Gallimard.

Cioran, Emile. 1956. La Tentation d'exister. Paris, Gallimard.

Cioran, Emile. 1960. Histoire et utopie. Paris, Gallimard.

Cioran, Emile. 1964. La Chute dans le temps. Paris, Gallimard.

Cioran, Emile. 1973. De l'inconvénient d'être né. Paris, Gallimard.

Cioran, Emile. 1995. Conversaciones. Barcelona, Tusquets.

Deleuze, Gilles y Félix Guattari. 1978 [1975]. Kafka: por una literatura menor. México, Era.

El Gharbi Salah. 2010. Yasmina Reza ou le théâtre des paradoxes. Paris, L'Harmattan.

Elias, Norbert. 2016 [1939]. El proceso de la civilización. Investigaciones sociogenéticas y psicogenéticas. México, Fondo de Cultura Económica.

GuÉnoun, Denis, 2005. Avez-vous lu Reza?: Une invitation philosophique. Paris, Albin Michel. 
Destinos afines: Emile Cioran, Yasmina Reza y la apología de la impugnación

Guiguere, Amanda. 2010. The Plays of Yasmina Reza on the English and American Stage. Jefferson, McFarland.

Grau, Maite y Carlos CAneque. 2007. Cioran, el pesimista seductor. Conversaciones con Fernando Savater, Simone Bou, Matei Calinescu, Ana Simon, Philippe Garnier, Ion Agheana. Barcelona, Sirpus.

Jaccomard, Hélène. 2013. Les Fruits de la passion. Le théâtre de Yasmina Reza. Berna, Peter Lang.

JACCOMARD, Hélène. 2016. "The Business of Violence in Yasmina Reza's God of Carnage" in French Forum 41 (3), 241-255.

JACCOMARD, Hélène. 2016. "L'humour comme arme: Le cas du Dieu du carnage de Yasmina Reza" in French Cultural Studies, 27(2), 190-198.

NaIPaul, V.S. 1987. The Enigma of Arrival. Londres, Viking Press.

RezA, Yasmina. 1987. Conversations après un enterrement. Paris, Albin Michel.

Reza, Yasmina. 1994. Art. Paris, Actes Sud.

Reza, Yasmina. 1997. Hammerklavier. Paris, Albin Michel.

RezA, Yasmina. [1995]1999. Une désolation. Paris, Albin Michel, 1999.

RezA, Yasmina. [1995] 2009. L'homme du hasard. Paris, Albin Michel.

RezA, Yasmina . [2001] 2017. Trois versions de la vie. Paris, Gallimard.

RezA, Yasmina. 2005. Dans la luge d'Arthur Schopenhauer. Paris, Albin Michel.

RezA, Yasmina . 2005. Nulle part. Paris, Albin Michel.

Reza, Yasmina. [2006] 2017. Le dieu du carnage. Paris, Gallimard.

Reza, Yasmina. 2013. Heureux les heureux. Paris, Flammarion.

Reza, Yasmina. 2016. Babylone. Paris, Flammarion.

Serrano, Montserrat. 2013. “Conversations après un enterrament: l'exquise obscenité de Yasmina Reza et sa "stratégie des poireaux" in Studi francesi 170, 416-424.

Simmel, George. 2012. El extranjero. Sociología del extraño. Madrid, Sequitur.

Simmonet, Dominique .2000. "J'écris sur le fil de l'essentiel". L'express, 13 de enero de 2000. <https://www.lexpress.fr/culture/livre/j-ecris-sur-le-fil-de-l-essentiel_797940.html> [13/06/2020].

SontaG, Susan. 1969. Styles of Radical Will. New York, Farrar, Straus and Giroux.

Tulbure, Corina Nicoleta. 2016. De Emil Cioran a Cioran: análisis de un discurso político. Tesis Doctoral, Universidad de Barcelona. 